\title{
FREE AND OPEN SOURCE SOFTWARE IN LOW-INCOME COUNTRIES: EMERGENT PROPERTIES?
}

\author{
Panel
}

\author{
Gianluca Miscione \\ University of Oslo, Norway \\ Dorothy Gordon \\ Advanced Information Technology Institute, Ghana \\ Kevin Johnston \\ University of Cape Town, South Africa
}

Free and Open Source Software (FOSS) is becoming an increasingly important element in strategies for development and implementation of information and communication technologies (ICT) in low-income countries (LICs). Such initiatives often have strong public sector orientation, as government ICT policies are expected to shape and support further socio-economical development. The usual mismatch between bureaucracies and trajectories of development initiatives (mostly run by international agencies) provides a promising field for empirical research.

This panel intends to discuss the connection between FOSS and organisational learning in contexts where usual assumptions about them cannot be taken-forgranted. It will be argued that the relevance of open technologies as public goods rests in allowing increased organisational learning in public administrations. Such a focus on the organisational aspects would complement existing studies on economical relevance of FOSS.

Common assumptions about FOSS dynamics emphasize the spontaneity of open and distributed development, as the FOSS-related organisations emerged on themselves. This panel proposal invites to explore what are the hidden regulations which constrain or en-act development, use, further development, and further use of FOSS-based ICT in LICs. These processes need to be understood to be explicitly considered in ICT for development policies. With this aim, three cases are presented and discussed, two from Africa and one from Kerala, a Southern state of India. 


\section{Challenges of IT decision-making for government in Africa and the implications for e-government solutions}

\section{Dorothy K. Gordon}

Governments all over Africa are engaged in the rapid deployment of new ICT systems intended to improve efficiency and improve G2C services. There is increasing interest in Africa from globally recognized companies that are in the business of marketing solutions. Also some donor agencies aggressively link funding with procurement of solutions designed by their nationals.

Companies in the local IT ecosystem benefit from a subsidiary market in the area of customization of proprietary solutions in order to adapt them to local needs. The high cost of these solutions and the relative paucity in government experience in large-scale IT procurement raises issues relating to fiscal management.

On the other hand the capacity for FOSS deployment and maintenance is weak in Africa. Local FOSS businesses find the environment difficult for a variety of reasons. What real options exist for transferring knowledge and building capacities in these areas? Is there a viable strategy for informing Governments of their options in the face of aggressive marketing of proprietary solutions? What is the role of local FOSS businesses? What policy elements could ensure a level playing field?

\section{Free/Libre \& Open Source Software (FLOSS/OSS) in low income countries}

\section{Kevin Johnston}

In the paper "Why South Africans don't FLOSS?" (with Dr Seymour, published in IBIMA, 2005 International Conference proceedings) we attempted to identify the factors that influence and limit the usage and intended usage of Free/Libre Open Source Software (FLOSS) within South Africa. Private and public sectors were examined.

We found that South African (SA) Small Medium Enterprises (SMEs) are often in favour of purchasing proprietary software rather than using OSS, as seek immediate resolution of technological issues, brand equity is important (tried \& tested), and risk of unknown.

Strategically, SA government has expressed strong intentions to use OSS since 2001, given its focus on local skill development, foreign exchange exposure and national security. On a practical level, we found limited OSS usage within the SA government. Political influences and risks associated with the scale and complexity of large government organisations nullify their OSS strategic usage intent. Through the need to leverage off their existing skill base and infrastructure, 
and the political pressure to eliminate additional risk by not going through unchartered territory, government remains tied to proprietary software.

If software procurement was predominantly cost driven, OSS would be considered and used by more organisations. Too few people are aware of what OSS can achieve and of the multiple success stories. Unless OSS distributors aggressively reorient themselves towards marketing, it will be impossible for them to effectively compete with proprietary organisations such as Microsoft.

In surveys of key issues for Chief Information Officers in South Africa, OSS did not feature at all. It should be noted that the list represented issues that CIOs regard as important, and not necessarily as problematic.

Organisations need to be aware that OSS can alter and shape strategy without senior management being aware of it. Staff can and do download OSS onto corporate platforms without permission (as it's free) or authority. This software may then start to be used and integrated into the business and business processes, and so changes the strategy.

Organisations need to be aware that although OSS is free, using it is not free, there are costs to run it on hardware, people costs, data conversion costs, etc.

\section{Situating FOSS for organisational learning}

\section{Gianluca Miscione}

The Kerala case moves from the development and implementation of a project by an international action-research network, locally supported by the government. The case involves the implementation of reporting software for aggregated health data from the public health system in primary health care facilities in the region of the capital. The argument addresses FOSS-related emphatic expectations for emancipation in the "knowledge society" on one side [4], and implementation and use, on the other. Then, a meso-level between global trends and local specificities is identified as crucial in situating FOSS for development potentialities. FOSS technologies are locally desirable both for practical and ideological reasons: practically, the software is expected to be more under control of the local authorities and developers' team. Ideologically, the Kerala government sustains that FOSS can be used to enact and guarantee cooperation and communal property, which is more consistent to its own ideological dispositions and long term development strategies.

A crucial challenge for FOSS in LICs concerns the establishment of functioning and sustainable implementations. Given the novelty of organisational forms required and implied by FOSS, the local elaboration and eventual consolidation of FOSS-based systems cannot take place without going through trial and error heuristic. Because of this, it is relevant to relate the discourse surrounding and legitimizing FOSS, with the politics and practice of implementation. 
This case shows that the (formal and informal) institutional constraints which FOSS implies and relies on are fragmented or absent, whereas others can be relevant. Nevertheless, FOSS narrative proves to be present and effective both in negotiations between stakeholders, and in facilitating local participation to information system development. ${ }^{69}$

FOSS fluidity allows inscribing a variety of context-bound socio-technical arrangements [3], and can also avoid path-dependencies and vendors' lock-ins [6]. But this is not spontaneous: software development process needs to be designed and carried on in a way that allows local organisations to "indigenize" FOSS. $^{70}$

The interactions around local technical skills improvement, and the increased ability for organisations to formulate, express, negotiate, and inscribe their needs in technology is proposed as a chance for organisational learning. This is proposed as a case for discussion about co-evolution between remote organisations, and the (mutually) transformative character of FOSS and ICT.

\section{Panelists}

Dorothy K. Gordon is the Director-General of Ghana's Advanced Information Technology Institute (the Ghana-India Kofi Annan Centre of Excellence in ICT), which provides IT training and consulting and promotes context-appropriate R\&D in information and communication technology. As a specialist in international development with more than 20 years experience, she has consulted to businesses and governments and has worked globally in the public sector and with civil society organisations, with increasing management and leadership responsibilities. She is currently Chair of the E-Government Commission of WITFOR 2009 (the World IT Forum) and President of the IPv6 Forum-Ghana. She is also the Africa spokesperson and Eminent Expert for World Summit Awards-Ghana, and a member of the Champions Network of UNGAID (the UN Global Alliance for ICT for Development).

Kevin Johnston is currently senior lecturer and Head of Department of the Department of information Systems at the University of Cape Town (UCT), South Africa. Kevin taught Mathematics \& Science at High Schools, before working for 24 years in industry for companies such as Wilson-Rowntree, De Beers, Liberty Life, Lifegro (Legal \& General Volkskas) and BoE. He joined UCT in 2001 as Senior Lecturer in the Department of Information Systems. His main areas of interest are ICT Management and Project Management. He has presented papers at conferences in Africa, Americas, Asia, Australia, and Europe.

Gianluca Miscione received his Ph.D. in Information Systems and Organization from the Sociology Department of the University of Trento (Italy) with a dissertation focused on the interplay between information and

\footnotetext{
${ }^{69}$ Myths and narratives are discussed by Czarniawska [2] in Neoinstitutional terms. The legitimizing role of myth is clearly presented by Noir and Walsham [5] through a case from Kerala, as well.

${ }^{70}$ Camara and Fonseca [1] relates modalities of participation to code writing, and software modularity.
} 
communication technologies and health care change in "developing" contexts. At the University of Oslo, his research activity line is situated between information infrastructures and organisational studies. Gianluca can be reached at gianluca.miscione@gmail.com.

\section{References}

[1] Camara G. \& Fonseca F. (2007). Information policies and open source software in developing countries, Journal Of The American Society For Information Science And Technology, 58(1), 121-132.

[2] Czarniawska B. (1997). Narrating the organization: Dramas of institutional identity, University of Chicago Press, Chicago, 1997

[3] De Laet, M. \& Mol A. (2000). The Zimbabwe bush pump: Mechanics of a fluid technology, Social Studies of Science, 30, 225-263.

[4] Government of Kerala - Department of Information Technology (2007). Information technology policy - Towards an inclusive knowledge society, Thiruvananthapuram

[5] Noir C. \& Walsham G. (2007), The great legitimizer: ICT as myth and ceremony in the Indian Healthcare Sector, Information Technology \& People, 20(4), 313-333(21).

[6] Weerawarana S. \& Weeratunge J. (2004), Open source in developing countries, SIDA. 